\title{
Grouping of parts for co-processing on flexible rotor lines
}

\author{
Yevhen Bulenkov *, and Alexander Mikhaylov \\ Donetsk National Technical University, Department of Manufacturing Engineering, 58, Artyom \\ Street, Donetsk, Ukraine
}

\begin{abstract}
The problem of parts combining for group processing on flexible rotary lines is considered in this article. The advantages of group processing in a single tool unit in terms of performance and metal consumption of lines are presented in this article. The technique of parts combining for group processing is proposed in this paper.
\end{abstract}

\section{Introduction}

Fasteners are one of the most widespread products of mechanical engineering. Increase in efficiency of their production is an important task, thus works on improvement of technology of their production are conducted. Cold forming of bolts, made of micro-alloyed steel, is investigated [1] to enable elimination of thermal treatment. In the study reported in [2], two forging approaches, traditional multistep forging and injection forging, were analyzed by using a finite element method in order to improve production efficiency in automobile fasteners production. The technological modernity of a machine used during the production process of screws is evaluated too [3]. These works allow developing manufacturing techniques of screws, but this technology doesn't consider feature of manufacturing machines and lines. Production of screws on flexible rotor lines is the most effective way of their processing [4-6]. The known design methods for these lines [4-5] allow creating multinomenclature rotor lines on which several different products are made. At the same time, the known rotor lines do not allow to make large number of different parts at the same time. They possess insufficient flexibility. Works in the field of grouping of products for their joint processing are conducted. Authors of paper [7] propose to apply a modified discrete firefly algorithm to the machine loading problem of the flexible manufacturing systems. Grouping parts into families which can be produced by a cluster of machine cells is the cornerstone of cellular manufacturing is proposed in [8]. Optimization of the integrated part type selection problem and machine loading problem is described in [9]. These works allow us to propose new type of rotor lines. The flexible rotor lines offered by us [6] mean processing of several screws in the flexible tool node. Grouping of parts for co-processing is one of the main problems for these lines. Thus, finding a technique for grouping of parts is an actual task for production of screws on flexible rotor lines.

\footnotetext{
* Corresponding author: bulenkov@ukr.net
} 
The purpose of this article is finding a technique for grouping of parts for their coprocessing.

To achieve this goal it is necessary to examine features of new flexible rotor lines, connection between structure of line and a structure of products and features of grouping of parts for co-processing.

\section{Grouping of parts for their co-processing}

For the solution of objectives the new design of the flexible rotor machine is offered, where in each flexible working position several different products are processed. It should be noted that the different structures of a flow of products in the flexible rotor line means transfer of products with different forms and sizes by the same position.

Figure 1 shows a sample of a flexible rotor line, which provides processing of several sizes of goods in each working position. In this case, the figure shows two flexible rotor machines (TrM1 and TrM2) for goods transportation and one machine for goods processing (TM). This sample of flexible rotor line is a part of line for producing 20 different types of screws. In processing, goods come from transport rotor TrM1 and processed in group tool module (FIN) by one of the tools. After completion of the technological cycle of processing goods are transferred to the transport rotor TrM2. During idling in group tool module tool is replaced for processing other nomenclature by turning tool drum.

The parts made on the flexible automatic rotor line differ in a head form, diameter and length of a rod, a step of a thread and a form of a groove for the screw-driver.

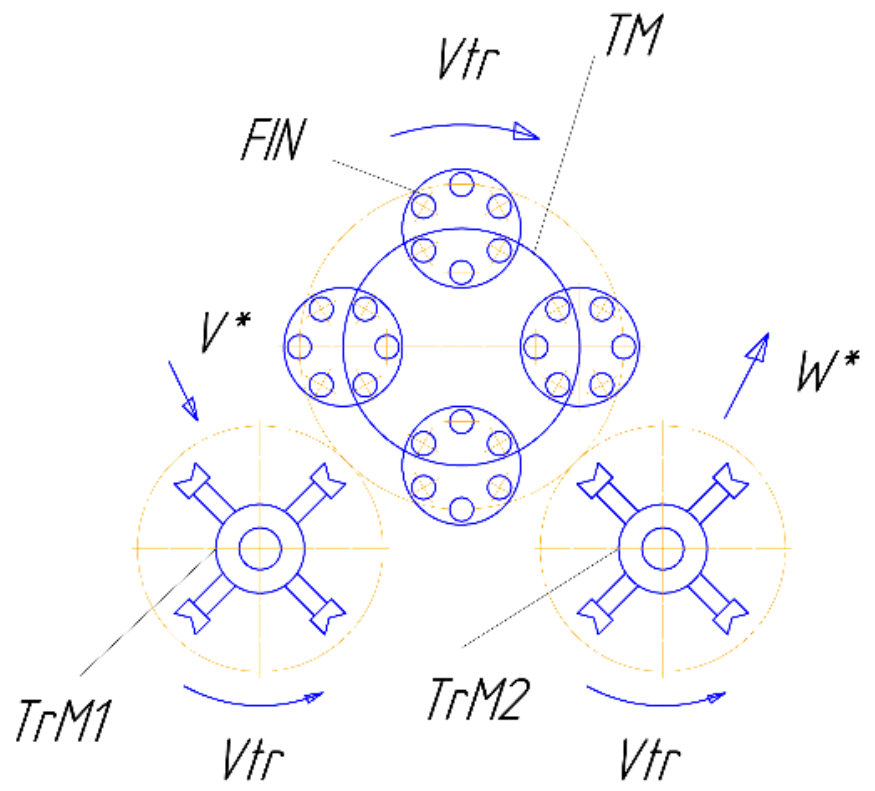

Fig. 1. A sample of a flexible rotor line.

During transportation products differ not only by the sizes, but also by a form of surfaces by which a transport rotor is holding them. At production of rod fasteners at different production phases their capture will be carried out as on cylindrical surfaces at stages of a shaping of a head, as on a threaded surface after knurl of a thread. 


$$
Q=P \cdot a=\frac{U p \cdot a}{T k},
$$

where $P$ - cyclic productivity of flexible rotor machine, number of pieces $/ \mathrm{min}$;;

$a$ - annual fund of operating time of the machine, min;

$U p$ - quantity of flexible tool nodes, piece;

$T k$ - time of a kinematic cycle, min.

Let's consider influence of different parts flow characteristics on the size of annual program of release of product with separate standard size $\mathrm{Q}_{\mathrm{A}}$.

For the flows differing in a ratio of quantity of standard sizes of products and quantities of flexible tool nodes, the annual program of release of products of one standard size is determined by dependence

$$
Q=Q_{A}+Q_{B}+\cdots Q_{S}=Z_{O} \cdot Q_{A}=\frac{U_{p} \cdot a}{T_{k}}, \quad Q_{A}=\frac{U_{p} \cdot a}{Z_{O} \cdot T_{k}},
$$

where Zo - quantity of instruments in flexible tool nodes, piece

At the same time, if $Z o<U p$, then the required annual program of release of products of one standard size is more than at equality of these values (Figure 3). When $Z o>U p$, the required annual program of one standard size products release is less than annual program of release of flexible tool node. Thus, it is necessary for ensuring loading of the flexible rotor line that the quantity of standard sizes of products was more than the number of flexible tool nodes in flexible rotor machine.

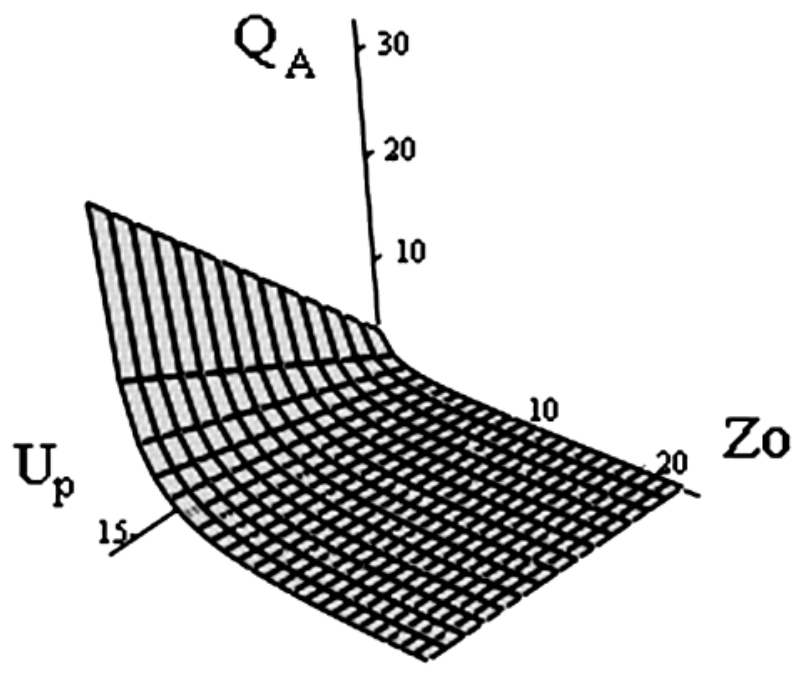

Fig. 3. Annual program of release of products with separate standard size.

The required annual program of release of products of one standard size in a case when flows differ in quantity of screws, processed at the same time, is found on similar expression:

$$
Q=Q_{A}+Q_{B}+\cdots Q_{S}=Z_{O} \cdot Q_{A}=\frac{t \cdot U_{p} \cdot a}{T_{k}}, \quad Q_{A}=\frac{t \cdot U_{p} \cdot a}{Z_{O} \cdot T_{k}},
$$

where $t$ - quantity of workpieces, processed at the same time.

Thus, with increase in quantity of standard sizes of products the required annual program of release of parts of one standard size remains without change. It is connected with the fact that in flexible instrumental node products of different standard sizes are 
processed. In case of single processing $(t=1)$ dependence will be similar represented in Figure 3. At the mixed processing with increase in quantity of screws, processed at the same time, the required annual program of release of parts of one standard size increases because in each flexible instrumental node identical products are processed.

Required annual programs of release of products of one standard size in the readjusted flexible rotor machines will be more, than in machines with simultaneous processing of products. It is connected with the fact that annual programs of production of products are invariable, and all pieces have to be processed in shorter time accordingly to readjustment. Thus, in this case the offered flexible rotor machines will be the most preferable as they provide a possibility of processing of the greatest number of standard sizes of products.

The structure of technology processes of products production is represented as set of elements - the operations of technology process (which are carried out in separate flexible rotor machine) and the relations between them (route compliance between parts and working positions). At the same time route compliance exerts very great influence on structure of flexible rotor machine (Figure 4), - at identical quantity of products different quantities of flexible tool nodes and intervals of shaping forces are possible.
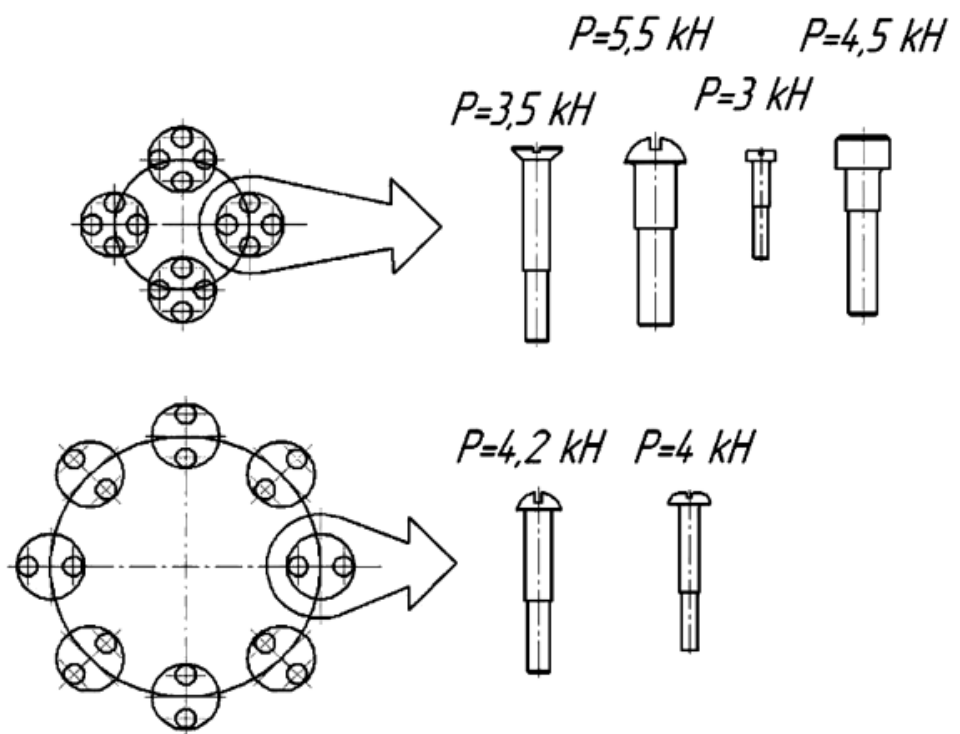

Fig. 4. Connection between structure of line and a structure of products.

Thus, the reasonable decision on grouping of parts for co-processing on flexible rotor lines can be made only after consideration of products routing in flexible rotor line and studying of products transportation.

Use of the theory of products routing as link between products manufacturing methods and structure of the line on which they will be made allows integrating development of technology processes of products production with structural synthesis of flexible rotor line.

The general sequence of development of technology processes of products production includes development of route technology process with the subsequent development of operations structure (Figure 5). It should be noted that process design of products production is carried out at the same time for all group of products. 


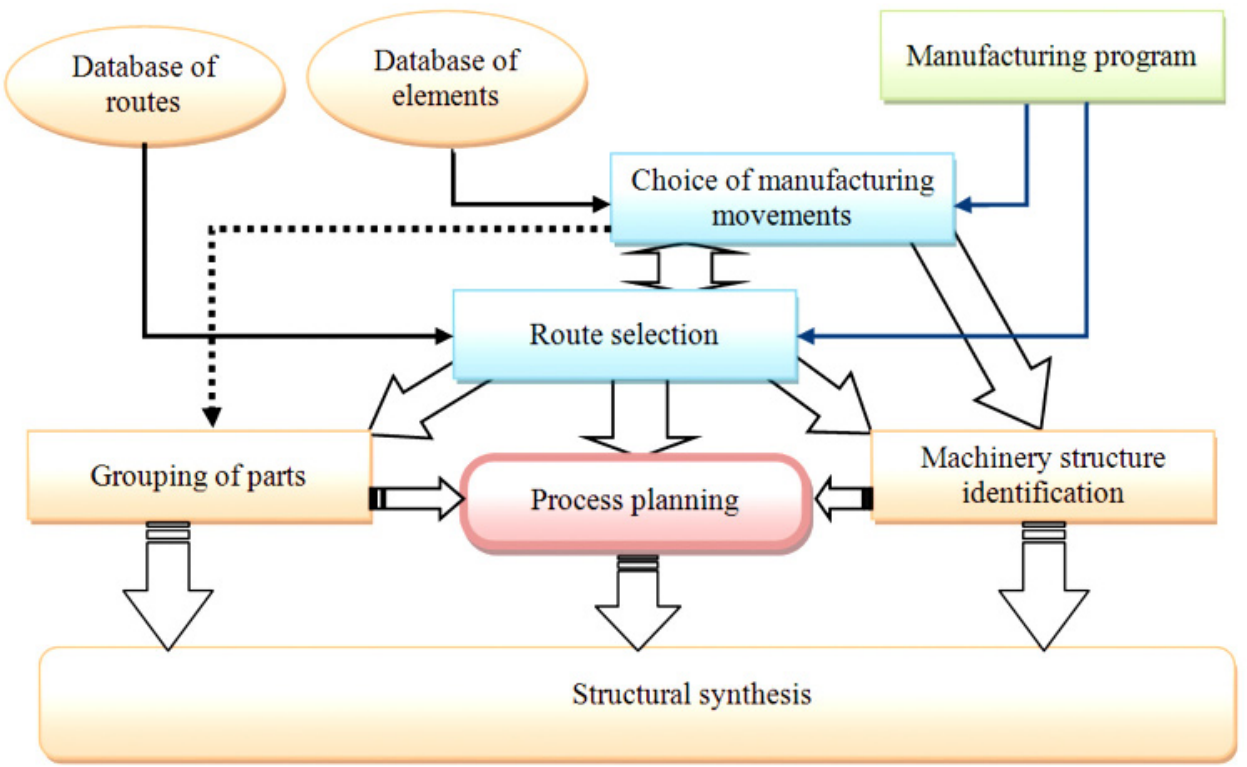

Fig. 5. The general sequence of development of technology processes of products production.

Design of technology process for products production is based on the choice of manufacturing movements and route selection. It is carried out parallel to machinery structure identification and grouping of parts.

\section{Results}

This work is dedicated to the development of design methods for flexible rotor lines that will combine several large-scale productions of products of different sizes in the mass diversified flow of goods by processing several sizes of goods in each group tool module. The developed method allows to group parts for co-processing on flexible rotor lines. The advantages of group processing in a single tool unit in terms of performance and metal consumption of lines are presented here.

\section{References}

1. L. Janíček, J. Petruška, B. Maroš, S. Rusz, J. of Mater. Proc. Tech., 125-126, 341-346 (2002).

2. C. Senyong, Q. Yi, MATEC Web of Conf., 21, 02007 (2015).

3. M. Ingaldi, K. Lestyánszka Škůrková, Tech. agricult., 17(4), 101-104 (2014)

4. L. Koshkin, Rotary and rotary conveyor lines. (Moscow, Machine building, 1986).

5. A. Mikhaylov, Basics of synthesis for flow-spatial technology systems of continuous action. (Donetsk, DNTU, 2002).

6. Y. Bulenkov, Progr. Tech. and Syst. for Mach.-Build. 46 30-37 (2013).

7. E. Bottani, P. Centobelli, R. Cerchione, L. Del Gaudio, T. Murino, Int. J. of Ind. Eng. Comp., 8, 363-372 (2017)

8. G. C. Onwubolu, The South Afr. J. of Ind. Eng., 9(1), (2011).

9. W. F. Mahmudy, AENG Int. J. of Comp. Sci., 42(3), 254-264 (2015). 